Original Research Paper

\title{
Overview of Certification Methodologies for Sustainable Constructions of Brazilian Buildings
}

\author{
Vanessa Silva Pugliero, Lorenzo Campos Coiado, Lia Lorena Pimentel, Ana Elisabete Paganelli Guimarães \\ de Avila Jacintho, Lia Toledo Moreira Mota and Alexandre de Assis Mota
}

CEATEC, Pontifical Catholic University of Campinas, Brazil

\author{
Article history \\ Received: 20-02-2015 \\ Revised: 22-04-2015 \\ Accepted: 04-05-2015 \\ Corresponding Author: \\ Alexandre de Assis Mota \\ CEATEC, Pontifical Catholic \\ University of Campinas, Brazil \\ Email: amota@puc-campinas.edu.br
}

\begin{abstract}
The terms "sustainable" and "environmentally-friendly" have been used in the construction industry field as a marketing appeal. The methodology to judge in which level a building is sustainable in Brazil is incipient, without orientation and hardly ever there is a diffusion of these methods inside Brazilian territory. Almost all developed countries have their appropriate certification methodology for sustainable constructions. Some of these methodologies could be adapted to developing countries. The aim of this work is to study the processes of environmental assessment in buildings that have been adapted in Brazil, comparing their parameters. Leadership in Energy and Environmental Design (LEED) imported from the United States and Alta Qualidade Ambiental (AQUA) adapted from HQE-France. Both methodologies were imported and adapted to the reality of Brazilian construction. It can be concluded that both certification processes qualitatively evaluate the specified parameters, such as energy, water and waste management, among others and need to be adapted to the countries where they will be applied, considering their specific climate conditions and legislations.
\end{abstract}

Keywords: Energy Efficiency, Sustainability, Sustainable Technology

\section{Introduction}

The buildings, activities and transportation services within cities may contribute to climate change because it requires energy sources and large volume of raw materials. In a construction the principles of sustainability can be incorporated even if it is a project or if it is a building under construction. The rampant consumption of natural resources has been the cause that sustainability has not been used properly. It can be noticed as a result the greenhouse effect and waste production which have decreased people's quality of living (e.g., Souza et al. (2007)).

Several changes have been made by construction companies to add environmental value by developing new practices (e.g., Lordsleem et al. (2006)). In the 1970s, with the oil crisis, several countries were forced to find alternatives to meet the energy demand. The sustainable plan in building constructions started by targeting the reduction of waste production, consumption of non renewable resources and energy consumption.

The concept of life cycle analysis required the development of methodologies for the evaluation of constructions. This fact forced countries to the environmental performance of constructions in the early 1990 s, mainly in Europe and North America (e.g., Silva et al. (2003)).

The evaluation of sustainable constructions helps the builders to achieve the required performance for the buildings with the least possible ecological damage, taking into account social, cultural and economical improvement in local, regional and global levels (e.g., Silva (2003)).

On average, LEED buildings use 18-39\% less energy per floor area than their conventional counterparts. Green buildings can contribute with substantial energy savings, but further work needs to be done to define green building rating schemes to ensure more consistent success at the individual building level (e.g., Newsham et al. (2009)).

Researches conducted by (Bodach and Hamhaber, 2010) have shown a high potential to increase energy efficiency in social housing in emerging countries like Brazil. The implementation and analysis of energy efficiency measures and policy recommendations can contribute dramatically to the goal to dampen the rapid growth of energy demand in these countries. 
Sustainable buildings use wisely natural resources (materials, water and energy) to provide comfort to the users, reducing costs over the lifetime of the building. These buildings also minimize the changes in the environment which they are placed. The first point to consider, when dealing with this type of construction, is that the concerns should start from the initial stages of planning and design and should continue during the construction, operation and maintenance stages. The design of the building is an important step for constructors to discuss integrated solutions to achieve high performance of the building throughout its useful life, considering the environmental, social and economical resource management factors and material specification. The introduction of the sustainability mechanisms in a building can represent to the project a lot of environmental changes inside the sector of civil construction in order to adapt the building to sustainability affording up the development opportunities for the sector (e.g., Fossati and Lamberts (2008)).

Each system of environmental certification of buildings has its predominant features and specific requirements for performance (e.g., Brito et al. (2008)).

Many methods for environmental certification were developed, starting in the 90 's when it became necessary to compare them so that the architects and engineers could have a better foundation for the development of sustainable projects. Lee and Burnett (2008), related sixty buildings and compared the evaluation on parameters of energy through the certification methods HK-BEAM, BREEAM and LEED concluding that the difference in methods of assessing energy use, landmark buildings, simulation tools and performance criteria do not affect the evaluation results and buildings that had excellent energy performance in HK-BEAM, BREEAM and LEED are among the best $5 \%$ of the market.

\section{Certifications Methodology for Sustainable Constructions}

AQUA

The methodology Alta Qualidade Ambiental (AQUA) or High Environmental Quality (HEQ) were imported from Haute Qualité Enviromentale (HQE) France to Brazil. AQUA has four big categories such as "Green-construction", "Green-management", "Comfort" and "Health".

The methods of AQUA are based on quantities (evaluation of methods, measurements, calculations) and qualitative (descriptions of the measurement adopted) elements.

AQUA has no scope for application of certification regarding to the use and occupancy of the building. In the certification guide there are some factors that help achieving environmental performance after the delivery of a building. The technical reference for this certification is based on the SGE (Enterprise Management System) which assesses the environmental management system by the company and defines the QAE (Environmental Quality of Development) that measures the technical performance and architectural construction (e.g., FV (2014)).

AQUA evaluates the building through four categories with subdivisions as shown in Table 1.

Category 1 "Relation of the building with its surroundings" can receive a positive evaluation when the building has an easy access for buses, bicycles and cars. Categories 4 and 5 are met when specified electrical equipment and economic toilet in order to reduce energy and water consumption respectively.

The sixth category "Waste management" is met when the construction site is poorly organized avoiding losses of packaging materials, which is fundamental for selective garbage collection and its proper disposal and the possibility of recovery of waste in the work itself.

For families "Health", "Sanitary quality of the air" and "Sanitary quality of the environment" categories the parameters to achieve the certification change depending on the different types of buildings. Nowadays there are technical references for three types of buildings: "Office and School Buildings", "Hotels" and "Residential Buildings".

\section{LEED for New Construction V.2.2}

The LEED program imposes six categories for buildings with credits and sub-credits with a preestablished number. There are categories with prerequisites that must be complied. There is a simple certification when the building received between 26 points and 32 points; between 33 and 38 points it obtains the silver certification; between 39 and 51 points it obtains gold certification and between 52 and 69 points it obtains the platinum certification.

The first category is "Sustainable Sites". It has a prerequisite and more than fourteen subcategories such as "Site Selection", "Development Density and Community Connectivity", "Alternative Transportation", "Brownfield Redevelopment", "Site Development", "Heat Island Effect", "Light Pollution Reduction" and "Storm water Design". This first category affords 14 points to a building at a total and the prerequisite "Construction Activity Pollution Prevention" must be accomplished.

The second category is Water Efficiency. It has three main credits including "Water Efficient Landscaping", "Innovative Wastewater Technologies" and "Water Use Reduction". This category does not have prerequisites and affords five points to a building at a total. 
Table 1. Categories evaluated by AQUA

\begin{tabular}{lll}
\hline Family & Category & Description \\
\hline Eco-construction & 1 & Relation of the building with its surroundings \\
& 2 & Choice of products, systems and construction processes \\
Eco-Management & 3 & Building site with low environmental impact \\
& 4 & Energy management \\
& 5 & Water management \\
Comfort & 6 & Waste management use and operation of the building \\
& 7 & Maintenance-Permanence of environmental performance \\
& 9 & Hygrothermal comfort \\
Health & 10 & Acoustic comfort \\
& 11 & Visual comfort \\
& 12 & Olfactory comfort \\
& 13 & Sanitary quality of the environment \\
& 14 & Sanitary quality of the air \\
\hline
\end{tabular}

The third category is "Energy and Atmosphere" that has three prerequisites: "Fundamental Commissioning of the Building Energy Systems", "Minimum Energy Performance" and "Fundamental Refrigerant Management" and the credits are "Optimize Energy Performance", "On-Site Renewable Energy", "Enhanced Commissioning", "Enhanced Refrigerant Management", "Measurement and Verification" and "Green Power". This category affords 17 possible points to a building.

The fourth category is "Material and Resources" that has one prerequisite ("Storage and Collection of Recyclables") and other seven credits such as "Building Reuse", "Materials Reuse", "Recycled Content", "Regional Materials", "Rapidly Renewable Materials" and "Certified Wood". This category adds 13 possible points to a building.

The fifth category is "Indoor Environmental Quality" that has two prerequisites ("Minimum IAQ Performance" and "Environmental Tobacco Smoke (ETS) Control"). The credits are "Outdoor Air Delivery Monitoring", "Increased Ventilation", "Construction IAQ Management Plan", "Construction IAQ Management Plan", "Low-Emitting Materials", "Indoor Chemical and Pollutant Source Control", "Controllability of Systems", "Thermal Comfort" and "Daylight and Views" Adding 15 possible points to a building.

The sixth category has no prerequisites and opens opportunities to constructor to implement sustainable increments to the construction. There are four subcategories about "Innovation in Design" and "LEED Accredited Professional" to divulgate the LEED's Certification (e.g., USGBC (2005)).

\section{Comparison between Aqua and LEED V2.2}

\section{Surroundings}

The AQUA requests to create drainage to control the floods, to manage nuisance from the construction site such as waste and noise and to ensure access of neighborhood at landscape. The construction should influence the least possible in the existing situation on site before the construction of the building. On the other hand, LEED requests the reduction of soil sealing, reduction of light pollution at night and the heat island effect and remediation of degraded areas.

\section{Indoor}

The AQUA's methodology proposes that the indoor ventilation system does not suffer interferences from generating economy and comfort. It also proposes to ensure the quality of collected rainwater, to sanitize waste storage sites and equipment that may come into contact with them. The LEED methodology proposes the control of gases emissions and cigarette smoke (the suggestions are to prohibit smoking in the building except in designated smoking areas, to allow this activity in areas at least 8 meters away from buildings entries), the easy control of lighting and thermal systems, to provide visibility at exterior of the building, to quantify the savings for equipment and to improve the energy performance of building by reducing the building dependence of the electrical energy network over time.

\section{Environmental Quality}

The AQUA methodology stimulates less polluting transport, the use of renewable energy, the preservation of ecosystems; the building needs an infrastructure to collect, to limit, sort and dispose the final waste in a safely and hygienic way. The LEED certification requires easy accessibility to the collector of recyclable waste not dangerous; to reduce car dependency; to use alternative fuels; to reduce 50 or $100 \%$ of the potable water consume for irrigation (the reuse of rainwater is a possible solution to potable water reduction); not building on sites high ecological importance and to protect the natural resource.

\section{Building Materials and Maintenance}

The LEED certification encourages the use of recycled materials in the pre and post-occupancy; the reuse of walls, floors and roofs; to prefer regional materials and certified wood; to choose products CFC-free or that collaborate with 
global warming or to pose risks to human health as paints, carpets, adhesives and sealants. The AQUA methodology aims to select products that support the environment, durability, comfort, health and economy of water and energy; to choose products with easy maintenance and accessibility and repairs them regularly.

Tables 2 and 3 show the parameters of the AQUA and LEED v2.2 methodologies separated into groups relating to the construction site management, waste management and choice of products indicating the goals of each methodology in the evaluation process.

\section{Certification Process}

The AQUA certification tends to improve the certification process to the extent that the enterpriser reports the environmental performance desired and the performance achieved by SGE and the Vanzolini Foundation concludes the certification of the building through the qualitative parameters. On the other hand, LEED Version 2.2 has 69 credits equivalent to 69 points, there is no weight with the credits although there is more concentration of points in one category than another to complete final certification. The builder can innovate its topics of certification.

\section{Electromagnetic Field}

The concern about electromagnetic pollution in buildings was pioneered by AQUA certification process. In the technical document for buildings under construction, the behavioral aspects concerning electromagnetic emissions are presented. These characteristics are not directly related to the built environment, but instead in better equipment utilization and good practices, focused on electromagnetic field issues (FV, 2014).

In telecommunications systems sections, the concern about electromagnetic radiation generated by the $\mathrm{Wi}-\mathrm{Fi}$ networks and regular phones is reported, mainly for wireless IT networks, considering its fast growth recently.

In the electrical power system, the main concern is fluorescent lightning. The certification indicates to building users to maintain a safe distance of these lamps, but lacks the specification of this minimum distance. Table 4 synthesizes the best practices to avoid electromagnetic fields in AQUA certification.

Table 2. Comparison of management on several issues, comparing the merits of the AQUA and LEED NC v2.2

\begin{tabular}{|c|c|c|c|}
\hline & AQUA & LEED NC v2.2 & Objectives \\
\hline $\begin{array}{l}\text { Construction } \\
\text { site management }\end{array}$ & $\begin{array}{l}\text { >Choice of products, } \\
\text { systems and processes } \\
\text { > The construction sites with } \\
\text { low environmental impacts } \\
\text { > acoustic comfort } \\
>\text { Comfort olfactory }\end{array}$ & $>_{-}$Air quality plan & $\begin{array}{l}\text { AQUA: Manage noise pollution and } \\
\text { waste at the construction site } \\
\text { LEED: Attend to the issues that may } \\
\text { present health risks, reuse of existing } \\
\text { building materials }\end{array}$ \\
\hline Waste management & $\begin{array}{l}\text { >-The building and its surroundings } \\
\text { > Waste management in use and } \\
\text { operation of the building } \\
\text { >_Quality of health environments }\end{array}$ & $\begin{array}{l}\text { >_Deposit and collected } \\
\text { of recyclable materials } \\
\text { >_Reuse of materials } \\
\text { >_Construction Waste } \\
\text { Management } \\
\text { > Recycled Content }\end{array}$ & $\begin{array}{l}\text { AQUA: Collection infrastructure, } \\
\text { limitation, sorting and disposal of } \\
\text { waste safely and hygiene. } \\
\text { LEED: Easy access to the collector of } \\
\text { recyclable waste, reuse walls, ceilings and } \\
\text { roofs to repair and reform activities, } \\
\text { maintaining non-structural elements of } \\
\text { the interior of the building, waste } \\
\text { destined for reuse, recover and reuse } \\
\text { materials on site. Encourage the use of } \\
\text { recycled pre and post occupancy. }\end{array}$ \\
\hline
\end{tabular}

Table 3. Comparison of choice of products in several issues, comparing the methods AQUA and LEED v2.2

\begin{tabular}{|c|c|c|c|}
\hline & AQUA & LEED NC v2.2 & Objectives \\
\hline Choose products & $\begin{array}{l}\text { >_Choice of products, } \\
\text { systems and processes } \\
\text { >Energy management } \\
\text { > Maintenance } \\
\text { >Comfort hygrothermal } \\
>\text { acoustic comfort } \\
\text { > visual comfort } \\
\text { >Comfort olfactive } \\
\text { > Quality of health environments } \\
\text { > Air Quality Health } \\
>\text { Quality sanitary water }\end{array}$ & $\begin{array}{l}\text { > Island Effect Reduction } \\
\text { > Disuse CFCs* } \\
\text { > Improving the Use of } \\
\text { Refrigerant Gases } \\
\text { > Low-emitting materials } \\
\text { (paints, carpets, adhesives } \\
\text { and sealants and composite } \\
\text { wood and agrofibras) } \\
\text { >Control of Pollutants and } \\
\text { chemicals } \\
\text { > Reuse of materials } \\
\text { > Recycled Content } \\
\text { > Regional Materials } \\
\text { > Materials Quick Renewal } \\
\text { > Certified Wood }\end{array}$ & $\begin{array}{l}\text { AQUA: Products that support the } \\
\text { environment, } \\
\text { durability, comfort and health } \\
\text { LEED: Use products that reduce } \\
\text { heat absorption and do not put } \\
\text { CFCs into the atmosphere, not to } \\
\text { collaborate with global warming. } \\
\text { Reusing existing building materials } \\
\text { and encourage the use of recycled } \\
\text { pre and post occupancy. } \\
\text { Give preference to local products } \\
\text { and are from renewable raw materials. } \\
\text { Use certified wood. }\end{array}$ \\
\hline
\end{tabular}


Table 4. Information about best practices to avoid electromagnetic fields in AQUA certification

\begin{tabular}{ll}
\hline AQUA \\
\hline Electromagnetic field & $>$ Avoid the use of compact fluorescent lamps and table lamps (keep a safe distance from the lamp). \\
& $>$ Turn off wireless networks (Wi-Fi) and electrical appliances when not in use. \\
& $>$ Regular phones with DECT technology for ECO mode, if available. \\
& $>$ Prioritize the use of appliances that generate the lowest possible magnetic field \\
\hline
\end{tabular}

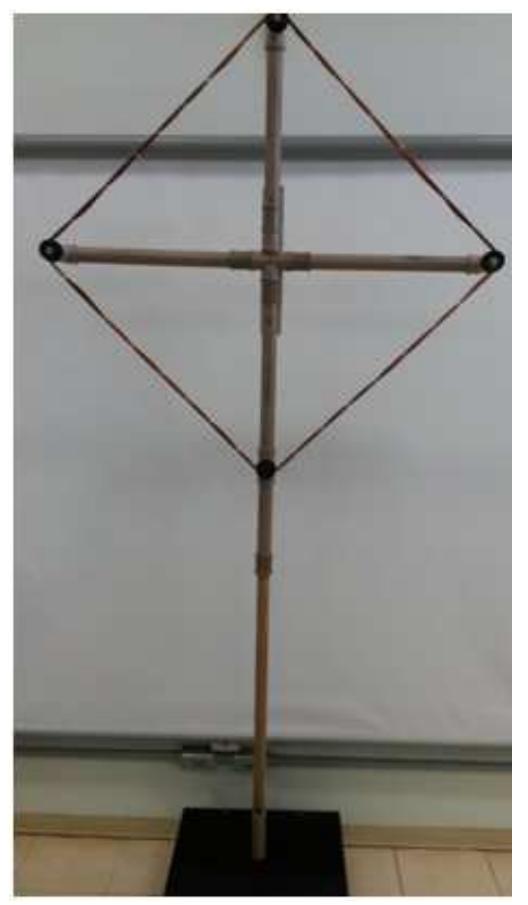

Fig. 1. Electromagnetic radiation antenna prototype

At Pontifical Catholic University of Campinas (PUCCampinas), recent research developments in the area resulted in an antenna prototype that is able to measure the electromagnetic magnetic field emitted from sources that operate at low frequencies (in the range of $60 \mathrm{~Hz}$ ). This antenna has been used in the Brazilian AQUA certification context, to measure the magnetic field in the vicinity of buildings. Figure 1 illustrates the antenna developed for this purpose.

\section{Conclusion}

Both AQUA and LEED methodologies include sustainable parameters at building with some differences. These methodologies need to be adapted to the countries where they will be applied, considering their specific climate conditions and legislations.

Both certification processes evaluate qualitatively the specified parameters, such as energy, water and waste management, among others. The main difference between LEED and AQUA is the emphasis given to these parameters. One can observe that both systems evaluated parameters are similar though divided into different categories. The LEED certification requires differentiated score between the parameters and some of them should be compulsorily met, while the AQUA methodology allows you to choose which parameters will be fulfilled.

All criteria for both certifications must be adapted to building, being aware if one parameter does not interfere negatively in the other one. Nowadays, there are specific certifications of AQUA and the LEED to each kind of building according to their future occupation. The certificated buildings can be recognized by its commitment with social, economic and environmental questions.

\section{Acknowledgment}

The authors would like to thank $\mathrm{CNPq}$ and the Pontifical Catholic University of Campinas for the financial support to this work.

\section{Author's Contributions}

Vanessa Silva Pugliero: Was the main responsible for the global bibliographic revision about Certification Methodologies for Sustainable Constructions of Brazilian Buildings and contributed to the writing of the manuscript.

Lorenzo Campos Coiado: Was the main responsible for the topic Electromagnetic Field and contributed to the writing of the manuscript.

Lia Lorena Pimentel and Ana Elisabete Paganelli Guimarães de Avila Jacintho: Coordinated the work and contributed to the writing of the manuscript.

Lia Toledo Moreira Mota and Alexandre de Assis Mota: Organized the comparison between AQUA and LEED certification methodologies and the topic about electromagnetic field and contributed to the writing of the manuscript

\section{Ethics}

This article is original and contains unpublished materials. The corresponding author confirms that all of the other authors have read and approved the manuscript and no ethical issues involved.

\section{References}

Bodach, S. and J. Hamhaber, 2010. Energy efficiency in social housing: Opportunities and barriers from a case study in Brazil. Energy Policy, 38: 7898-7910. DOI: 10.1016/J.ENPOL.2010.09.009. 
Brito, A.C., F. Vittorino and M. Akutsu, 2008. Environmental assessment of buildings. Téchne, São Paulo.

Fossati, M. and R. Lamberts, 2008. Methodology for assessing the sustainability of building projects: The case of offices in Florianopolis. Proceedings of the 12th Brazilian Meeting of Technology of the Built Environment (TBE' 08).

FV, 2014. AQUA-ALTA QUALIDADE AMBIENTAL. Fundação Vanzolini. Management ReferenceAQUA Certification.

Lee, W.L. and J. Burnett, 2008. Benchmarking energy use assessment of HK-BEAM, BREEAM and LEED. Build. Environ., 43: 1882-1891.

Lordsleem, A.C., A.M. Silveira, B.G. Oliveira, G.H. Pires and W.C. Takewaga, 2006. Implementation, Monitoring and Actions for Waste Management: The Experience in construction site of the City of São Paulo. Proceedings of the 11th Brazilian Meeting of Technology in the Built Environment, (TBE`06).
Newsham, G.R., S. Mancini and B.J. Birt, 2009. Do LEED-certified buildings save energy? Energy Build., 41: 897-905.

DOI: 10.1016/J.ENBUILD.2009.03.014

Silva, V.G., 2003. Sustainability assessment of office buildings in Brazil: Guidelines and methodological basis. PhD Thesis, University of São Paulo.

Silva, V.G., G.M. Silva and V. Agopyan, 2003. Assessment of buildings in Brazil: Environmental assessment to sustainability assessment (in portuguese). Revista Ambiente Construído.

Souza, C.H.C., C.M.R. Illanes, I.P.B. Bohadana, L.C. Coelho and L.T. Rodrigues et al., 2007. Reference center for sustainable buildings in urban areas: Design for the headquarters of the Friends of the Earth.

USGBC, 2005. LEED for new constructions and major renovations v. 2.2. U.S. Green Building Council. 